\title{
Campus Physical Environment Accessibility for Person with Disabilities in the Ethiopian Public Universities
}

\author{
Abdulfettah Muzemil \\ Lecturer in Special Needs Education, Department of Special Needs and Inclusive Education, Jimma University, Ethiopia \\ Email: abdu1222@yahoo.com \\ http://dx.doi.org/10.18415/ijmmu.v5i5.455
}

\begin{abstract}
The study has been conducted aiming to explore the perception of PWDs regarding the accessibility of universities Physical environment for their needs in five purposively selected public universities of Ethiopia. Students with physical disabilities and visual impairments were participants of the study. The study employed survey design to answer the basic questions of the research. Questionnaire has been used as exclusive data collection tool. In addition, quantitative analysis method has been used to analyze the collected data. The result of the study revealed that, in general, respondents believed that the universities buildings and overall campuses physical environment were inaccessible for the needs of PWDs. The study also investigated the most common perceived campus physical environment barriers for PWDs such as inaccessible classrooms, libraries, bookstores, auditoriums, dining halls, dorms, circulation areas, corridors and bathrooms. In addition, campus shops, parks, museums, students' clinic and banks were perceived as not been barrier free to be easily accessed by PWDs. Furthermore, poor ramp designs, lack of elevators and lack of accessible building entrances were also perceived as barriers for PWDs.
\end{abstract}

Keywords: Accessibility; Building Accessibility; Physical Environment Accessibility

\section{Introduction}

According to the World Bank and World Health Organization report, Persons with Disabilities (PWDs) currently constitute up to 15 per cent of the world's population and most of these persons live in rural areas in developing countries. Many of these persons lack an equal access to health care, education, job opportunities and other necessary services. One of these challenges that prevent their access to possible independence and their use of public spaces is lack of attention to their physical and mobility needs, resulting in their isolation and deprivation of their human rights. The issue of access to public buildings has received little attention in Ethiopia, leading to the deprivation of a large number of people from enjoying their legal rights on an equal footing with other members of the society. As a result, disability has caused many problems at family and societal levels, because PWDs have been deprived of accessing their human rights such as the rights to health and education and other human rights, they have 
been unable to utilize their talents and their families cannot properly look after them as there are no special rehabilitation and care centers.

Education is one of the fundamental human rights that every human being should have access. It is a pathway to a successful life and career and this applies to everyone including PWDs. The issue of equal access and opportunities for SWDs at different levels of education draws attention of different stakeholders. Access to higher education, which is the focus in this research, should be crafted in line with the needs of persons with disabilities. The question for equal and fair access is growing voice among students with disabilities, who successfully completed secondary education (Barnes., 2004).

As noted in Putnam (2003), although access of PWDs to higher education is slowly gaining momentum from time to time and from place to place, equality with regard to access has remained unattainable in most countries of the world including Ethiopia. The traditional barriers for inaccessibility of higher education for those with disabilities might arise from variety of circumstances, particularly from two false premises: the one is their needs are assumed to be expensive to cover, and the second is PWDs are under rated that cannot perform required qualification criteria for higher education (Willeh., 2002).

Regarding undermining attitude in the Ethiopian context, Tirussew (2005, p.3) indicated "in Ethiopia, PWDs are perceived as "weak", "hopeless", " dependent", and "unable to learn" and "subject of charity". By assessing and revealing the conditions, challenges as well as by suggesting recommendations, the situation of SWDscould be improved. When it comes to the education of PWDs especially in the higher learning institutes, barriers and difficulties are numerous.

With regard to higher education accessibility for students with disabilities, barriers include physical, architectural, service deliveries, provisions of learning materials and equipment, attitudinal and cultural influences. Apart from the multitude of barriers that affect the education of students with disabilities, physical barriers are visibly challenging these students. Free movement in the university campuses is assumed to be the right (IDEA., 1997). Accessible classrooms, dormitories, halls, dining rooms, recreational areas, library, service delivery units, dormitories, exit passageways in emergency situations are all elements of physical accessibility, however these basic conditions are not adequately met (Tirussew., 1994; Tirussew \& Ellena., 2000).

Failure to fulfill those provisions might hinder their success (IDEA, 2004). Though there are some changes in the new buildings, AAU SWDshave problems due to lack of special arrangement made to accommodate their needs (Tirussew., 1994; Misrak., 2005). The PWDA provides for accessibility as one of the rights of person with disability. Accessibility in this regard extends to eliminating barriers that are present in accessing and using public buildings by PWDs.

As Evans (1998), noted accessibility is shift services from simply trying to fit the child into "normal settings"; it is a supplemental support for their disabilities or special needs and promotes the child's overall development in an optimal setting. Putnam, Geenen, (2003) defined accessibility as Inclusive, that respect of difference and celebration of diversity. Their focuses are creating environments responsive to the differing developmental capacities, needs, and potentials of all students. It is also adjustments and accommodations that incorporate creative solutions. In laws and standards on accessibility, accessibility refers to what the law requires to enable the reaching or approaching of something (in this regard a HEIs). Accessibility is the presence of facilities that enable the easy entry and use of a public building in this regard by person with disability.

With all the challenges, the improvement of educational participation of SWDsis a vital issue (Jorgensen., S, Fitchen., 2005). To increase participation of SWDsin the higher institutes, funding, long term planning., opening and widening study options are to be considered to mention a few (McKenzie \& Schweitez., 2001). Whereas physical accessibility to higher educational institutions, public buildings and places is one of the reasons to assist the participation of PWDs in the education and community and the 
realization of their rights, the pre hand observation indicates that no considerable attention has been paid to physical accessibility and various categories of PWDs cannot enjoy their legal rights and access public buildings and places due to various types of disabilities, although accessibility has been enshrined in the relevant national and international laws. The present research was conducted with a view to studying the present situation and focusing on the issue of physical accessibility of higher education institutions as a legal right for PWDs so as to draw the attention of the relevant authorities to the issues.

Higher education has been through a period of major change since the mid-1980s. A massive expansion in student numbers has been coupled with a reduction in funding and greater accountability. Within this demanding context, pressure has also been applied to institutions to improve accessibility for people with disability, most recently through changes in legislation with the amendment to the Disability Discrimination Act.

Nowadays over 40 universities enroll huge number of students. It is observed that there is dramatically increment in the institutions annual students' enrollment rate. Although the number of universities and enrollment rates goes inline, the number of SWDs who attend the institution annually is very low. Various reasons have been identified for low enrollment rates of SWDs in Ethiopian universities. Among the major challenges inaccessible physical environment, problems to have appropriate assistive devices and curricular related issues appear first. Those who joined the universities have experience challenges of different type ranging from academic to social.

It seems that SWDs in Ethiopian HEIs face challenges of different type that affect their academic and social life at the time of their study period. Therefore, it is expected that students should have special and disability related supports from their respective universities to successfully engage in learning activities and accomplish their studies. Thus, this study attempts to investigate the situations of SWDs in HEIs. The study predominantly focuses on challenges of accessibilities, in particular about common and specific physical barriers, services provisions, participation rates and related issues. The overall intention of this study is to identify challenges students with visual and physical impairments face and the provisions made to support their studies in the universities.

Despite the demands faced by institutions, there were definite signs of progress in provision for students with disability. Most institutions had at least one designated disability officer and a senior manager with responsibility for disability issues. Studies conducted in the area revealed gaps between policy and practice and showed that significant barriers remain to the participation of students with disability in higher educational institutions. Most importantly there has been identified areas needing particular attention such as physical environment accessibility, teaching and learning, monitoring and evaluation and staff development.

Depending on their particular impairment, most of the students experiences barriers to accessing their education relating to the physical environment or teaching and learning (or both) at some point during their studies. In addition, the institution and course choice of some students has been affected by physical access issues. Besides classrooms, ICT lab and dormitories, the access to dining halls, toilet rooms, wash rooms and playgrounds has been the great constraints on SWDS specifically on those with physical and visual impairments.

In general, the study aimed to assess the Ethiopian Universities physical environment accessibility for PWDs, and to identify the major physical environment barriers that limits the maximum participation of PWDs in the campus activities. 


\section{Methodology}

This study was a descriptive exploratory study that utilized a quantitative approach via survey research methods. It involved administering a survey to available and a randomly selected sample of students with physical disabilities and visual impairments in some selected public universities. In doing this the researchers tried to explore the sampled universities physical environment accessibility for PWDs.

Data source of the study were students with physical disabilities and visual impairments sampled from five public universities. Throughout the study both primary and secondary data sources have been employed. Students who participated on reporting the survey were the primary sources of the study, and secondary sources such as different publications, books, magazine and documented materials have been used throughout the study.

The study was conducted in five purposively selected government universities in central and south western Ethiopia. The universities were Addis Ababa University, Welkite University, Jimma University, Bonga University and Mizan Tepi University. The population of the study were students with disabilities. Among students, only students with physical disabilities and visual impairments were invited to participate in the study. A total of 122 participants were selected both through random and availability techniques from the study sites. To be more specific, 46 PWDs (26 students with physical disabilities, and 20 students with visual impairments) from Addis Ababa University, 34 SWDs (20 students with physical disabilities, and 14 students with visual impairments) from Jimma University, 16 students with physical disabilities from Welkite University, 8 students with physical disabilities from Bonga University and 18 students with physical disabilities from Mizan Tepi University were participants of the study. Finally, all sampled students in the selected universities had made to report the survey.

The study employed questionnaire as exclusive data collection tools. Following extensive review of related literatures, questionnaires dominantly with close ended items which has three parts modified and developed. The first part of the questionnaire was intended to gather demographic characteristics of respondents, the second part described about the educational backgrounds of respondents and the perception they posse regarding their respective universities of physical environment accessibility. And the final part of the questionnaire was likert type scales that has been measured on a scale range from 1 to 5 (1 strongly disagree, 2 disagree, 3 undecided, 4 agree and 5 strongly agree). Before actual use the questionnaire has been piloted. Here vague items, unclear idea or ambiguous items were corrected based on the feedback obtained from pilot study. Furthermore, experts of the area reviewed and evaluate the questions' validity to assure whether it measure the variables that might be appropriate for the study. Finally, quantitative means of data analysis was employed. Specifically, both descriptive statics such as percentage, frequency, mean and standard deviation, and inferential statistics such as ANOVA and t-test has been employed for the analysis of gathered data. SPSS software package version 20 has been used to analyze the statics.

\section{Result}

Both descriptive and inferential statistics has been used for the analyses of collected data. First, descriptive statistics about samples perceived campus buildings accessibility and overall campus physical environment accessibility for PWDs, and Likert-scale data were calculated. In addition, the study tried to explore the existed association between the campus buildings accessibility for PWDs, and overall physical environment accessibility for PWDS and all demographic variables. Results of independent $t$ tests and ANOVA indicated that there were statistically significant differences between three groups only (groups of impairment type, university they have been enrolled and academic status) on samples perception of Campus buildings accessibility for PWDs, and Overall campus physical environment accessibility for PWDs. Whereas there were no statistical differences observed between the groups of 
Sex, Age range, Severity level, Age of onset and course years of study on samples perception of Campus buildings accessibility for PWDs, and Overall campus physical environment accessibility for PWDs.

\section{Descriptive Statistics}

The descriptive data for the sample $(\mathrm{N}=122)$, about perceived campus buildings accessibility for PWDs, and overall campus physical environment accessibility for PWDs are presented in table 1 . The study attempted to examine the participants' general perception of the campus buildings accessibility and overall campus physical environment accessibility for PWDs. In order to generate such information from the respondents' two statements were presented in the survey which asked respondents to indicate their agreement level by selecting either inaccessible, undecided or accessible. The findings of the study on these two general aspects of campus accessibility revealed that much differences were not observed on respondents' perception of campus buildings and overall campus physical environment inaccessibility for PWDs. However, comparatively more number of students agreed on overall campus physical environment inaccessibility for PWDs. In more detail, concerning campus buildings accessibility for PWDs half $50 \%(n=61)$ of participants said the campus buildings are inaccessible to be easily used by PWDs. Respondents who seemed the buildings of the universities accessible for PWDs were $27.9 \%(\mathrm{n}=$ $34)$, and $22.1 \%(\mathrm{n}=27)$ of them neither said accessible nor inaccessible remained undecided. Regarding the overall physical environment inaccessibility more students agreed on overall campus physical environment inaccessibility than who agreed on the universities buildings inaccessibility for PWDs. Out of the total participants $62.3 \%(n=76)$ of them agreed by the overall campus physical environment inaccessibility, and these who undecided and who said the overall campus physical environment is accessible have equal number $18.9 \%(\mathrm{n}=23)$. Based on the findings, it can be concluded that majority of PWDs have been challenged in universities due to inaccessibility of campus buildings and overall campus physical environment for their special needs.

Table 1 Campus buildings and overall campus physical environment accessibility for PWDs

\begin{tabular}{llll}
\hline \multicolumn{1}{c}{ Variables } & Perception & No & $\%$ \\
\hline \multirow{3}{*}{ Buildings accessibility } & Inaccessible & 61 & 50.0 \\
& Undecided & 27 & 22.1 \\
& Accessible & 34 & 27.9 \\
& Total & 122 & 100.0 \\
\hline \multirow{3}{*}{ Overall physical environment accessibility } & Inaccessible & 76 & 62.3 \\
& Undecided & 23 & 18.9 \\
& Accessible & 23 & 18.9 \\
& Total & 122 & 100.0 \\
\hline
\end{tabular}

In addition to frequency-percentage analysis (Table 1), mean analysis was conducted for the respondents report on the two general statements which might better described the universities physical environment accessibility for PWDs, i.e. campus buildings accessibility for PWDs, and overall campus physical environment accessibility for PWDs. When the findings of the data explored, Table 2 shows that the mean of the response for the statement accessibility of campus buildings for PWDs $n=122$ is 1.78 , while it is 1.57 for the statement overall campus physical environment accessibility for PWDs $n=122,(1$ inaccessible, 2 undecided and 3 accessible). In general, it indicates that respondents perceived inaccessible to undecided on the level of universities physical environment accessibility for the needs of PWDs. Further analysis of the obtained data also showed that there is a statistically significant differences between respondents report based on their demographic background. More specifically, a statistically significant difference has observed on the respondents impairment type, university they have been 
enrolled and academic status. The analysis has been done through One Way Analysis of Variance (ANOVA) and independent samples t-test.

Table 2 Means for buildings and overall physical environment accessibility for PWDs

\begin{tabular}{llll}
\hline Variables & No & Mean & SD \\
\hline Buildings accessibility & 122 & 1.78 & .858 \\
Overall physical environment accessibility & 122 & 1.57 & .792 \\
\hline
\end{tabular}

\section{Likert-Scale Analysis}

In the study likert-type scale has been used to examine the respondents' perception of universities physical environment accessibility for PWDs in more specific and detail manner. The responses on the likert-type scale has been measured on a scale range from 1 to 5 (1 strongly disagree, 2 disagree, 3 undecided, 4 agree and 5 strongly agree). Statements presented in the likert scale intended to gather specific information from respondents regarding physical environment accessibility of universities for PWDs. In general, the statements of the likert scale focused to obtain further information on the accessibility of universities physical environment for PWDs such as learning rooms, libraries, laboratories, dormitories, corridors, circulation areas and bathrooms. In addition, statement on the accessibility of playgrounds and recreation cites of the universities for PWDs were among the areas included to be investigated on the likert scale. Finally, statements that described the accessibility of the universities service provision buildings such as Banks and shopping centers were also included on the likert scale.

The analysis of statements of the likert scale presented in the following sections. The analysis has been made through comparing Mean and Standard Deviation (SD) of each statements. Statements with similar Mean and SD responses grouped and presented in a table and followed by word interpretation of tabulated data. Furthermore, the analysis of the likert scale has been made for each disability types (students with physical disability and students with visual impairment).

The first four statements of the Likert scale describes issues of campus accessibility related with mobility of PWDs from place to place. Regarding campus accessibility for PWDs to move freely from place to place statements such as availability of accessible transportation, barrier free sidewalks, easily readable and understandable signs, and availability of curb cuts on the street to access sidewalks listed. And the mean analysis in Table 3 shows that to some extent participants with the two impairment groups possess similar perception, i.e. they perceived the campuses were inaccessibility for PWDs to move freely from place to place.

The mean for availability of accessible transportation in the campus for the needs of students with physical disabilities and visual impairment were 2.01 and 1.62 respectively. For the case of statement sidewalks of the campus are barrier free, perceived mean of students with physical disability and visual impairment were 2.14 and 2.38 respectively. Again, 2.18 and 2.29 for students with physical disability and visual impairment respectively were perceived mean for statement campus signs are easy to read and understand. Likewise, the mean perceived availability of curb cuts on the streets in key areas to allow users to access sidewalks were 2.18 for students with physical disability and 2.48 for students with visual impairment. It suggested that students with physical disabilities and visual impairments have been troubled to move freely in the campus due to inaccessible transportation service, barrier full sidewalks, unavailability of readable and understandable signs, and absence of curb cuts on the street to access sidewalks. 
Table 3 Campus accessibility for mobility of PWDs

\begin{tabular}{llllll}
\hline & & \multicolumn{3}{c}{ Disability type } \\
& & \multicolumn{3}{c}{$\begin{array}{c}\text { Physical } \\
\text { Nisability }\end{array}$} & \multicolumn{2}{c}{ Visual impairment } \\
& & Mean & SD & Mean & SD \\
\hline 1. & Accessible transportations are available on campus for my & 2.01 & .864 & 1.62 & .493 \\
& needs & & & & \\
2. & Sidewalks of the campus are barrier-free & 2.14 & 1.008 & 2.38 & 1.155 \\
3. $\quad$ Campus signs are easy to read and understand & 2.18 & .929 & 2.29 & 1.060 \\
4. $\quad \begin{array}{l}\text { There are curb cuts on the streets in key areas to allow users } \\
\text { to access sidewalks }\end{array}$ & 2.18 & .929 & 2.44 & 1.307 \\
\hline
\end{tabular}

In the Likert scale statements concerning accessibility of campus building entrances, bathrooms, corridors and circulation areas for the needs of the two impairment groups were also presented. In this regard, the perception of the two impairment groups showed variation. Table 4 shows that the mean perceived adequacy of accessible building entrances and ease for identification for students with physical disabilities was 2.14, while it was 2.50 for students with visual impairments. Similarly, the mean perceived adequacy of accessible bathrooms in buildings for students with physical disabilities was 1.94, and it was 3.29 for students with visual impairments. Again, differences observed on perception of accessibility of corridors and circulation areas in the two impairment groups. The perceived mean for corridors and circulation areas being free from barriers for students with physical disabilities was 2.17, while 3.62 for students with visual impairments. The obtained data indicates students with physical disabilities disagreed regarding campus buildings entrances, bathrooms, corridors and circulation areas on being accessible for their needs. However, students with visual impairments remained undecided concerning accessibility of campus buildings entrances and bathrooms for their needs, and they agreed on the corridors and circulation areas being accessible for their needs.

Table 4 Accessibility of campus building entrances, bathrooms, corridors and circulation areas for PWDS

\begin{tabular}{|c|c|c|c|c|c|}
\hline \multirow{3}{*}{ No } & \multirow{3}{*}{ Statements } & \multicolumn{4}{|c|}{ Disability type } \\
\hline & & \multicolumn{2}{|c|}{ Physical disability } & \multicolumn{2}{|c|}{ Visual impairment } \\
\hline & & Mean & SD & Mean & $\mathrm{SD}$ \\
\hline 5. & $\begin{array}{l}\text { Accessible building entrances are adequate and easy to } \\
\text { identify }\end{array}$ & 2.14 & .985 & 2.50 & $\begin{array}{l}1.13 \\
5\end{array}$ \\
\hline 6. & $\begin{array}{l}\text { There are enough accessible bathrooms for the buildings } \\
\text { I use }\end{array}$ & 1.94 & .939 & 3.29 & $\begin{array}{l}1.38 \\
2\end{array}$ \\
\hline 7. & Corridors and circulation areas are free from barriers & 2.17 & .913 & 3.62 & .985 \\
\hline
\end{tabular}

As shown in Table 5, the two impairment groups agreed regarding accessibility of interior doors, classroom lighting and classroom spaces. The mean for perceived adequacy and accessibility of interior doors for needs of students with physical disabilities is 3.61, and 4.03 is for students with visual impairments. Similar agreement level is obtained regarding adequacy of classroom lighting that is, mean 
of 3.70 for students with physical disabilities, and mean of 3.85 is for students with visual impairments. Also perceived mean of classroom space adequacy for the needs of students with physical disabilities is 3.64, and 3.91 is for students with visual impairments. Based on the findings of the study it can be concluded that campus buildings are accessible for the needs of PWDs in the areas of interior doors, classroom lighting and classroom spaces.

Table 5 Accessibility of campus interior doors, classroom lighting and spaces

\begin{tabular}{llllll}
\hline \multirow{2}{*}{ No } & \multicolumn{2}{c}{ Statements } & \multicolumn{4}{c}{ Disability type } \\
& & \multicolumn{3}{c}{ Physical disability } & \multicolumn{2}{c}{ Visual impairment } \\
& & Mean & SD & Mean & SD \\
\hline 8. & Interior doors are adequate for my needs and accessible & 3.61 & .940 & 4.03 & .904 \\
9. & Classroom lighting is adequate for my needs & 3.70 & .961 & 3.85 & .500 \\
$10 . \quad$ Classroom space is adequate for my needs & 3.64 & .912 & 3.91 & .830 \\
\hline
\end{tabular}

To examine whether students with disabilities have been took part on campus activities like other students without disabilities statement was presented on the likert scale. The statement read as "I am as involved with campus activities as much as students who do not have disabilities". The obtained result shows that students with the two impairment groups disagreed with the above statement. The mean for students with physical disabilities is 2.45 , and the mean for students with visual impairment is 2.41 . Tabular presentation of the data appears in Table 6. Therefore, it can be said that PWDs were not as actively participate in the campus activities as these without disabilities.

Table 6 Students' participation on campus activities

\begin{tabular}{|c|c|c|c|c|c|}
\hline \multirow{3}{*}{ No } & \multirow{3}{*}{ Statements } & \multicolumn{4}{|c|}{ Disability type } \\
\hline & & \multicolumn{2}{|c|}{ Physical disability } & \multicolumn{2}{|c|}{$\begin{array}{l}\text { Visual } \\
\text { impairment }\end{array}$} \\
\hline & & Mean & SD & Mean & SD \\
\hline 11. & $\begin{array}{l}\text { I am as involved with campus activities as much as students } \\
\text { who do not have disabilities }\end{array}$ & 2.45 & 1.049 & 2.41 & 1.184 \\
\hline
\end{tabular}

To investigate the condition related with traffic safety of students with disabilities in the campus statements were presented on the Likert scale to be rated by the respondents. As indicated in Table 7 below students with physical disabilities disagreed on the availability of traffic signals at cross walks. Again, they believed that the roads, streets and crossings of the campus were not free of barriers. The mean for availability of traffic signals at cross walks to control the peace of traffic was 2.14 and the mean for roads, streets and crossing of the campus are barrier free was 2.13, while for the case of students with visual impairments they remained undecided for both cases with perceived mean of 2.65 for the availability of traffic signals at cross walks to control the pace of traffic, and perceived mean of 3.09 for roads, streets and crossing of the campus are free of barriers. The findings of the study suggests that students with physical disabilities felt that the campus environment is not favorable to move safely. However, students with visual impairments were undecided as to whether or not that the traffic signals, and roads, streets and crossings are in their favour. 
Table 7 Accessibility of roads and streets for PWDs

\begin{tabular}{|c|c|c|c|c|c|}
\hline \multirow{3}{*}{ No } & \multirow{3}{*}{ Statements } & \multicolumn{4}{|c|}{ Disability type } \\
\hline & & \multicolumn{2}{|c|}{ Physical disability } & \multicolumn{2}{|c|}{ Visual impairment } \\
\hline & & Mean & SD & Mean & SD \\
\hline 12. & $\begin{array}{l}\text { There is a traffic signals at cross walks to control the } \\
\text { pace of traffic }\end{array}$ & 2.14 & .961 & 2.65 & 1.300 \\
\hline 13. & $\begin{array}{l}\text { Roads, streets and crossings of the university are free of } \\
\text { barriers. }\end{array}$ & 2.13 & .814 & 3.09 & 1.240 \\
\hline
\end{tabular}

Regarding accessibility of service provision sites and institutions which found in the campus such as parks, museums, theater/concert halls, Banks, students' clinic, and shopping centers three statements presented for respondents to rate their agreement levels. And most of them undecided whether or not accessible for their needs. In more detail, Table 8 shows that the mean perceived accessibility of recreation sites such as parks, museums, etc. for students with physical disabilities was 2.78 , while it was 2.62 was for students with visual impairments. Regarding the mean perceived accessibility of movies, theaters and concert halls for students with physical disabilities and visual impairments were 3.11 and 3.24 respectively. Finally, the mean perceived accessibility of banks, students' clinic, shops and/or shopping centers for students with physical disabilities was 2.55 , while it was 3.50 for students with visual impairments. Based on the result of the study it can be said that PWDs neither agreed nor disagreed regarding the accessibility of service provision sites and institutions of their campus for their needs. However, students with visual impairments agreed on the accessibility of banks, students' clinic, shops and/or shopping centers for their needs.

Table 8 Accessibility of service provision institutions for PWDs

\begin{tabular}{|c|c|c|c|c|c|}
\hline \multirow{4}{*}{ No } & \multirow{4}{*}{ Statements } & \multicolumn{4}{|c|}{ Disability type } \\
\hline & & & & & \\
\hline & & \multicolumn{2}{|c|}{$\begin{array}{l}\text { Physical } \\
\text { disability }\end{array}$} & \multicolumn{2}{|c|}{$\begin{array}{l}\text { Visual } \\
\text { impairment }\end{array}$} \\
\hline & & Mean & $\mathrm{SD}$ & Mean & SD \\
\hline 14. & $\begin{array}{l}\text { Recreation sites such as parks, museums etc. are accessible } \\
\text { for my needs }\end{array}$ & 2.78 & 1.208 & 2.62 & 1.101 \\
\hline 15. & I can easily access movies, theaters and/or concert halls & 3.11 & 1.139 & 3.24 & 1.257 \\
\hline 16. & $\begin{array}{l}\text { Banks, students' clinic, shops and/or shopping centers of the } \\
\text { campus are located on a place where I can easily access }\end{array}$ & 2.55 & 1.134 & 3.50 & 1.080 \\
\hline
\end{tabular}

As it has been seen in Table 9 statements which is related with availability of ramps in the campus for wheelchair users and availability of auditory signals at crosswalks in the campus for students with visual impairments also appeared in the Likert scale. The perceived mean for the presence of ramps in the campus is 2.55 , it is near to undecided whether or not ramps available for wheelchair users to circumvent steps and uneven ground. Regarding the statement "there is auditory signals at cross walks" 
majority of the students with visual impairment showed their disagreement with mean of 2.32. As it is known, in Ethiopia the technology of auditory traffic signals has been introducing recently. And its presence is limited only for the capital city of the country. Therefore, the students report seems similar when compared with what the country's experience has in the area of auditory traffic signals in cross walks.

Table 9 Availability of ramps for PWDs

\begin{tabular}{|c|c|c|c|c|c|}
\hline \multirow{3}{*}{ No } & \multirow{3}{*}{ Statements } & \multicolumn{4}{|c|}{ Disability type } \\
\hline & & \multicolumn{2}{|c|}{ Physical disability } & \multicolumn{2}{|c|}{ Visual impairment } \\
\hline & & Mean & $\mathrm{SD}$ & Mean & SD \\
\hline 17. & $\begin{array}{l}\text { There are ramps for wheelchair users to circumvent steps } \\
\text { and uneven ground/There is auditory signals at cross } \\
\text { walks }\end{array}$ & 2.55 & 1.183 & 2.32 & 1.065 \\
\hline
\end{tabular}

In the study the accessibility of classrooms, libraries and laboratories, and the accessibility of dining rooms and dormitories were also examined. As it can be seen from Table 10 below, students with visual impairments felt that the learning rooms, libraries and laboratories are accessible for their needs, and its perceived mean was 3.71. Whereas, students with physical disabilities were undecided on the accessibility of the learning rooms, libraries and laboratories for their needs, and the perceived mean was 2.84. Somewhat similar to previous statements perceived responses were obtained from both groups for the statement accessibility of dining rooms and dormitories for their needs. The mean perceived accessibility of dining rooms and dormitories for students with visual impairments was 3.53, and the mean for students with physical disabilities was 2.65 . Based on the findings, it can be concluded that students with visual impairment perceived that buildings of the campus classrooms, libraries, laboratories, dining rooms and dormitories are accessible for their needs. Whereas, proportionally more students with physical disabilities perceived that buildings of the campus classrooms, libraries, laboratories, dining rooms and dormitories are built against their needs.

Table 10 Accessibility of classrooms, libraries and laboratories for PWDs

\begin{tabular}{|c|c|c|c|c|c|}
\hline \multirow{3}{*}{ No } & \multirow{3}{*}{ Statements } & \multicolumn{4}{|c|}{ Disability type } \\
\hline & & \multicolumn{2}{|c|}{$\begin{array}{l}\text { Physical } \\
\text { disability }\end{array}$} & \multicolumn{2}{|c|}{$\begin{array}{l}\text { Visual } \\
\text { impairment }\end{array}$} \\
\hline & & Mean & $\mathrm{SD}$ & Mean & $\mathrm{SD}$ \\
\hline 18. & $\begin{array}{l}\text { Classrooms, libraries and laboratories are on the ground } \\
\text { floor, or there is elevator, or classes could be relocated to the } \\
\text { ground floor, if necessary/Classrooms, libraries and } \\
\text { laboratories are accessible for my need }\end{array}$ & 2.84 & 1.113 & 3.71 & .799 \\
\hline 19. & $\begin{array}{l}\text { Dining rooms and dormitories are on the ground floor, or } \\
\text { there is elevator/Dining rooms and dormitories are accessible } \\
\text { for my need }\end{array}$ & 2.65 & 1.223 & 3.53 & .961 \\
\hline
\end{tabular}

Lastly, respondents were asked to rate their agreement level regarding the availability of accessible play grounds for their respective types of impairments. Table 11 indicates that the mean perceived availability of accessible play grounds for students with physical disabilities and visual impairments were 2.56 and 1.65 respectively. It implies that, students with physical disabilities were 
undecided on the accessibility or inaccessibility of campus playgrounds for them, however, students with visual impairments disagreed on the availability of accessible playgrounds on the campus for them.

Table 11 Accessibility of play grounds for PWDs

\begin{tabular}{llllll}
\hline \multirow{2}{*}{ No Statements } & \multicolumn{3}{c}{ Disability type } \\
& & \multicolumn{3}{c}{ Physical disability } & $\begin{array}{l}\text { Visual } \\
\text { impairment }\end{array}$ \\
& & Mean & SD & Mean & SD \\
\hline $20 . \quad$ There are accessible playgrounds in the campus & 2.56 & 1.183 & 1.65 & .691 \\
\hline
\end{tabular}

\section{Mean Level Differences due to Impairment Types}

To determine whether there is a significant difference in students' perception on campus buildings and over all campus physical environment accessibility for PWDs due to impairment type independent sample t-test was computed. The two groups of impairment types were physical impairment/disability and visual impairment. The result revealed that there was a statistically significant differences between the perception of the two impairment groups in case of campus building accessibility for PWDs, but statistically significant difference was not found between the two impairment groups perception for the statement overall campus physical environment accessibility for PWDs.

Regarding the statement campus buildings accessibility for PWDs, the result shows that there was significantly difference between the perceptions of the two impairment type groups at $\mathrm{p}<0.05, \mathrm{t}=-3.313$, $\mathrm{p}=.104$. The mean for perceived accessibility of campus buildings for students with physical disability ( $\mathrm{n}$ = 88) was 1.63 and the mean perceived accessibility of campus buildings for students with visual impairment ( $\mathrm{n}=34$ ) was 2.18 ( 1 inaccessible, 2 undecided and 3 accessible). The result indicates that, on average, students with both types of impairments undecided whether or not the buildings were accessible for their respective needs. However, comparatively more numbers of students with physical disabilities thought the campus buildings were inaccessible for their needs than students with visual impairments. Summary for the analysis of $t$-test data presented in Table 12 .

Table 12 Analysis of campus buildings and overall physical environment accessibility of campus for PWDs by impairment types

\begin{tabular}{lllllcl}
\hline Variable & Disability type & $\mathrm{N}$ & Mean & SD & $\mathrm{t}$ & sig \\
\hline Buildings accessibility & Physical disability & 88 & 1.63 & .092 & -3.313 & .001 \\
& Visual impairment & 34 & 2.18 & .904 & & \\
\hline
\end{tabular}

$\mathrm{p}<0.05$

\section{Mean Level Differences due to University}

ANOVA was computed to determine whether there is a significant difference in students' perception on campus buildings accessibility for PWDs, and overall campus physical environment accessibility for PWDs based on difference in university they have been enrolled. Students from five universities participated on the study. The universities were Jimma University, Addis Ababa University, 
Mizan Teppi University, Walkite University and Bonga University. The result of the study revealed that there is a statistically significant differences between the five university groups in each of the two statement categories.

Regarding the statement campus buildings accessibility for PWDs, as it is shown in Table 13 there is a statistically significant difference between the perceptions of the five university group students at $\mathrm{p}<0.05, \mathrm{~F}=7.819, \mathrm{p}=0.000$. Post Hoc Tukey HSD tests indicated that students who has been enrolled in Addis Ababa University were significantly differed in their perception of campuses building accessibility for PWDs from those students who enrolled in Bonga University. The mean score of Addis Ababa University students $(\mathrm{n}=46)$ is 2.28 , whereas it is 1.43 for Bonga University students $(\mathrm{n}=7)$. The result indicates that comparatively more students with disabilities of Addis Ababa University perceived their campus buildings neither accessible nor inaccessible for PWDs, but they perceived buildings accessibility for PWDs more positively than students with disabilities of Bonga University who perceived campus buildings are inaccessible for PWDs.

Table 13 Analysis of campus building accessibility for PWDs by university

\begin{tabular}{lllllll}
\hline Variable & University & $\mathrm{N}$ & Mean & SD & F & sig \\
\hline \multirow{3}{*}{ Buildings accessibility } & Jimma University & 34 & 1.47 & .748 & & \\
& Addis Ababa University & 46 & 2.28 & .886 & & \\
& Mizan Teppi University & 18 & 1.50 & .786 & 7.819 & 0.000 \\
& Walkite University & 17 & 1.47 & .514 & & \\
& Bonga University & 7 & 1.43 & .535 & & \\
& Total & 122 & 1.78 & .858 & & \\
\hline
\end{tabular}

$\mathrm{p}<0.05$

Regarding the statement overall campus physical environment accessibility for PWDs, Table 14 below indicates that there is a statistically significant difference between the perceptions of the five university group students at $\mathrm{p}<0.05, \mathrm{~F}=7.578, \mathrm{p}=0.000$. Post Hoc Tukey HSD tests indicated that students who have been enrolled in Addis Ababa University were significantly differed in their perception of overall campus physical environment accessibility for PWDs from those students who enrolled in Mizan Teppi University. The mean score of Addis Ababa University students $(n=46)$ is 2.02 , whereas it is 1.22 for Mizan Teppi University students $(\mathrm{n}=18)$. The obtained result indicates that comparatively more students with disabilities of Addis Ababa University perceived their overall campus physical environment neither accessible nor inaccessible for PWDs, but they perceived the campus overall physical environment more positively than students with disabilities of Mizan Teppi University who perceived the campus overall physical environment was inaccessible for PWDs.

Table 14 Analysis of campus overall physical environment accessibility for PWDs by university

\begin{tabular}{lllllll}
\hline Variable & University & $\mathrm{N}$ & Mean & SD & F & sig \\
\hline \multirow{3}{*}{ Overall physical environment } & Jimma University & 34 & 1.35 & .544 & & \\
accessibility & Addis Ababa University & 46 & 2.02 & .977 & & \\
& Mizan Teppi University & 18 & 1.22 & .428 & 7.578 & 0.000 \\
& Walkite University & 17 & 1.24 & .437 & & \\
& Bonga University & 7 & 1.29 & .488 & & \\
& Total & 122 & 1.57 & .792 & & \\
\hline
\end{tabular}

$\mathrm{p}<0.05$ 


\section{Mean Level Differences due to Academic Status}

Based on the self-report of students on their academic achievement ANOVA was run to determine whether there is a statistically significant difference on their perception of campus buildings accessibility for PWDs, and overall campus physical environment accessibility for PWDs. The reported academic status were low, medium and high. The obtained data on Table 15 indicates that a statistically significant differences between the three severity level groups observed only for the statement campus buildings accessibility for PWDs.

Concerning the statement campus buildings accessibility for PWDs, there is a statistically significant difference between the perceptions of the three academic result groups at $\mathrm{p}<0.05, \mathrm{~F}=4.895$, $\mathrm{p}=0.009$. Analysis of Post Hoc Tukey HSD tests result showed that students who reported high academic result were significantly differed in their perception of campuses building accessibility for PWDs from those students who reported low academic result. The mean score for students who reported high academic result $(n=29)$ is 2.14 , whereas it is 1.00 for those who reported low academic result $(n=4)$. Therefore it can be concluded that students who reported high academic result perceived their campus buildings neither accessible nor inaccessible for PWDs, however, they perceived campus buildings accessibility for PWDs more positively than students who reported low academic result, who perceived campus buildings are inaccessible for PWDs.

Table 15 Analysis of buildings and overall physical environment accessibility of universities for PWDs by academic status

\begin{tabular}{llccccc}
\hline Variables & Academic status & $\mathrm{N}$ & Mean & SD & F & Sig \\
\hline \multirow{3}{*}{ Buildings accessibility } & Low & 4 & 1.00 & .000 & & \\
& Medium & 89 & 1.70 & .831 & 4.895 & .009 \\
& High & 29 & 2.14 & .875 & & \\
& Total & 122 & 1.78 & .858 & & \\
\hline
\end{tabular}

$\mathrm{p}<0.05$

\section{Discussion}

As it has been explained in previous topics, the study focused on examining Ethiopian universities physical environment accessibility for students with disabilities. More specifically, it focused on examining campus buildings accessibility and overall campus physical environment accessibility for students with visual impairments and physical disabilities.

The analysis of the data showed, in general, students with disabilities perceived their respective university's buildings and overall physical environment to be inaccessible for their needs. It implies that universities should strive to improve its physical environment accessibility for the needs of PWDs, specifically, for these with physical disabilities and visual impairments. These findings are similar with previous researches conducted in various parts of the land, such as Steve Simonson (2012) who investigated that students with mobility impairments will be more likely to find the sidewalks on campus are not adequate for their needs. Problems with sidewalks are common at universities in the United Kane (2009). As sited by Ratan Sarkar (2016) ... However, research reveals that out of 722 Indian universities (Current as of 30th June 2015) not even a single one is completely disabled friendly. Research also revealed that only $0.1 \%$ students with disabilities are in mainstream educational institutions at the university level (N.C.P.E.D.P., 2004). The common barriers wheelchair users have been faced included narrow aisles, unavailability of ramps, or ramps to steep, heavy doors, no curb cuts, and obstructed wheel 
travel (Meyers., Anderson., Miller., Shipp., \& Hoenig., 2002). This showed as how the physical environment barrier affected the daily campus activities of PWDs.

In addition, the findings of the study also in line with previous research, as sited by Addis Ababa University department of special needs education research team 2014, Higher education accessibility barriers including physical, architectural, service deliveries, provisions of learning materials and equipment, attitudinal and cultural influences (IDEA., 1997; Kenny., 2004) are widely prevalent in the universities covered in the present study to the extent students get in to psychological problems hating their classes, education and, in cases, life in general. It shows that students with disabilities have been struggling by inaccessible campus physical environment.

Furthermore, as described above, students with disabilities perceived the universities physical environment inaccessible for the needs of PWDs. However, the study revealed that there were differences of opinion among respondents based on demographic backgrounds. Difference of opinion has been observed in two general areas among three different demographic background groups. The two areas of observed differences were campus buildings accessibility for PWDs, and overall campus physical environment accessibility for PWDs. And the three demographic groups which statistically significant differences of students' perceptions observed were impairment type, universities they have been enrolled and academic status. The study found that respondents had statistically significant different perception in the areas of campus buildings accessibility for PWDs based on impairment type groups. As indicated in the data analysis, in general, the two impairment groups undecided on either the campus buildings were accessible or inaccessible for PWDs. However, the majority of students with visual impairments either undecided on the accessibility of campus buildings for their needs or perceived that the campus buildings were accessible for their needs, while majority of students with physical disabilities undecided or thought that the campus buildings were inaccessible for their needs. It shows that students with physical disabilities were more likely to perceive that the campus buildings were inaccessible for their needs.

There was also a statistically significant difference in perceptions among respondents on the campus buildings accessibility for PWDs, and overall campus physical environment accessibility for PWDs when they were grouped by universities they have been enrolled. As shown in the data analysis, the majority of participants from Bonga University perceived either inaccessible or undecided that the campus buildings were in favour of their needs, compared to a majority of respondents from Addis Ababa University who either agreed that campus buildings were accessible for their needs or undecided on it. It indicates that participants of Bonga University were more likely to perceive that the campus buildings were inaccessible for their needs. In addition, as it has been shown in the data analysis, the majority of Mizan Teppi University participants perceived the overall campus physical environment inaccessible for their needs, compared to the majority of Addis Ababa University participants who were undecided, they perceived the overall campus physical environment were neither accessible nor inaccessible for their needs. It indicates that participants of Mizan Teppi University were more likely to perceive that the overall campus physical environment was inaccessible for their needs.

The final statistically significant difference in the perceptions of respondents found on the perception of campus buildings accessibility for PWDs when they were grouped by self-reported academic status. The analysis of data showed that the majority of students who reported high academic result undecided regarding the campus buildings accessibility for their needs, whereas, students who reported low academic result thought that the campus buildings were inaccessible for their needs. This shows that students who reported low academic status perceived the campus buildings as inaccessible for their needs.

In conclusion, the study investigated that many PWDs had difficulties in the physical environments of Ethiopian universities. There were several areas that the students with disabilities had difficulties in universities including accessing buildings, bathrooms, bookstores, campus shops, dining halls, dorms, and classrooms (Kane., 2009). The main problem areas for students with disabilities were 
poor ramp designs, lack of curb cuts, lack of working elevators, lack of accessible building entrances, narrow doors, inaccessible auditoriums, and small bathroom spaces (Holloway., 2001, Kane., 2009, Alrashidi., 2010).

\section{Conclusion}

Based on the findings and discussions made, the following conclusions are drawn:

- PWDs have been experiencing serious challenges in Ethiopian universities due to inaccessibility of its physical environment.

- The universities physical environment inaccessibility adversely affected the success and full participation of students with disabilities in their education.

- PWDs could not move freely in the campus environments. This was due to lack of appropriate transportation service, barrier full sidewalks, unavailability of readable and understandable signs, and absence of curb cuts on the street to access sidewalks. In addition, the roads, streets and crossings of the campuses were not free of barriers.

- The most common availed physical environment related barriers which limed the full participation of PWDs in the campuses were inaccessible classrooms, libraries, bookstores, auditoriums, dining halls, dorms, circulation areas, corridors and bathrooms. In addition, campus shops, parks, museums, students' clinic and banks were not been barrier free to be easily accessed by PWDs. Furthermore, poor ramp designs, lack of elevators and lack of accessible building entrances were also among the campuses common observed barriers for PWDs.

- The universities physical environment inaccessibility negatively affected students with disabilities to participate actively in the campus activities as these without disabilities.

\section{References}

Alrashidi, A. M. (2010). University Education and Students' Perceptions of Physical Disabilities at Kuwait University.

Barnes, C. (2004). Disability, Disability Studies and the Academy. In J. Swain., S. French, C.

Church, R. L., \& Marston, J. R. (2003). Measuring Accessibility for People with a Disability. Geographical Analysis.

Evans, J. L. (1998). Inclusive ECCD: A Fair Start for All Children. Coordinators' Notebook: An International Resource for Early Childhood Development, No.22. New York: UNICEF, the Consultative Group of Early Childhood Development.

Fichten, C. S. (1988). Students with Physical Disabilities in Higher Education: Attitudes and Beliefs that affect Integration. In H. E. Yuker (Ed.). New York: Springer.

Fuller, M., Healey, M., Bradley, A., Hall, T. (2004). Barriers to Learning: A Systematic Study of the Experience of Disabled Students in one University. Studies in Higher Education. 
Gray, D., Gould, M., \& Bickenbach, J. (2003). Environmental Barriers and Disability. Journal of Architectural and Planning Research.

Gliner, J., Morgan, G., \& Leech, N. (2009). Research Methods in Applied Settings An Integrated Approach to Design and Analysis. New York: Routledge.

Hall, P., \& Imrie, R. (1998). Architectural Practices and Disabling Design in the Built Environment. Environment and Planning B: Planning and Design, p. 409-425.

Holloway, S. (2001). The Experience of Higher Education from the Perspective of Disabled Students. Disability and Society, p. 597-615.

Individuals with Disabilities Education Act (IDEA), (2007).

Kane, J. (2009). The College Experience for Students with Physical Disabilities. Ann Arbor: Proquest LLC.

Kenny, M. (2004). Postsecondary Students with Disabilities and Perception of Faculty Members. The Journal for Vocational Special Needs Education.

Johnson, A. L. (2006). Students with Disabilities in Postsecondary Education: Barriers to Success and Implication to Professionals.

McKenzie, K., \& Schweitzer, R., (2001). Who Succeeds at University? Factors Predicting Academic Performance in First Year Australian University Students. Higher Education Research \& Development,

Meyers, A., Anderson, J., Miller, D., Shipp, K., \& Hoenig, H. (2002). Barriers, Facilitators, and Access for Wheelchair Users: Substantive and Methodologic Lessons from a Pilot Study of Environmental Effects.

Misrak Tarekegn (2006), Challenges and Opportunities of Access and Mobility in Addis Ababa; the Case of People, with Motor and Visual Impairments, Publisher Addis Ababa University School of Graduate Studies.

Putnam, M., Geenen, S., Powers, L., Saxton, M., Finney, S., \& Dautel, P. (2003). Health and Wellness: People with Disabilities Discuss Barriers and Facilitators to Well Being. Journal of Rehabilitation, 69(1): 37-45.

Shevlin, M., Kenny, M., \& McNeela, E. (2004). Participation in Higher Education for Students with Disabilities: an Irish Perspective.

Tirussew Teferra, \& Elina Lehtomaki. (2000). Towards Creating an Inclusive Learning Environment for Students with Disabilities: Perspectives of Addis Ababa University.

Tirussew Teferra, Savolainen H., Agdew R. \& Daneil D. (1995). Base Line Survey of Disabilities in Ethiopia. Institute of Educational Research, Addis Ababa University. Addis Ababa: Commercial Printing Enterprise.

Tirussew Teferra. (2005). Disability in Ethiopia: Issues, Insights and Implications. Addis Ababa University Printing Press.

Tirussew Teferra. (1994). Psychosocial and Educational Problems of Students with Disabilities in Addis Ababa University. Ethiopian Journal of Health Development 8(1), 1994. 
Tirussew Teferra. (1989). The Psychosocial and Educational Problems of Handicapped Students in Addis Ababa University (mimeographed). Institute of Educational Research, Addis Ababa University.

Willeh, T. (2002). Gavilan College Campus Diversity Climate Survey Project.

Willsher, L. (2009). The Lived Experience of Physically Disabled Adults in College. Ann Arbor: Proquest LLC.

\section{Copyrights}

Copyright for this article is retained by the author(s), with first publication rights granted to the journal.

This is an open-access article distributed under the terms and conditions of the Creative Commons Attribution license (http://creativecommons.org/licenses/by/4.0/). 